\title{
De la insubordinación a la cooptación: el sindicato petrolero y las movilizaciones de 1958 y 1959
}

\section{From Insubordination to Cooptation: The Oil Union and the Mobilizations of 1958 and 1959}

\author{
Héctor Luis Zarauz López \\ (D) https://orcid.org/0000-0001-5688-0666 \\ Instituto de Investigaciones Dr. José María Luis Mora, México \\ hzarauz@institutomora.edu.mx
}

Resumen: Los objetivos del artículo son reconstruir la movilización de los petroleros en los años de 1958 y 1959; observar las demandas y estrategias de lucha y, finalmente, analizar las tácticas del gobierno para mantener el control sobre este sindicato. En el desarrollo del trabajo se logra documentar las movilizaciones de los trabajadores petroleros en la ciudad de México en los años de 1958 y 1959, así como sus antecedentes. Se documentan las causas y formas de lucha y su asociación con otros sectores sociales, así como las estrategias de cooptación ejercidas por el gobierno mexicano. De esto se concluye que, a diferencia de otros movimientos, los petroleros recibieron un trato diferente por parte del gobierno. Esto, sumado a una estrategia de negociación, permitió que los líderes opositores se unieran al sistema sindical oficial. Todo lo anterior en un ambiente de enorme protesta social, liderado por los sindicatos afiliados al propio gobierno. El movimiento de los petroleros en estos años no ha sido estudiado; en general,

cómo citar: Zarauz López, H. L. (2019). De la insubordinación a la cooptación: el sindicato petrolero y las movilizaciones de 1958 y 1959. Secuencia (105), e1617. DoI: https://doi.org/10.18234/secuencia.v0i105.1617

CC 1 Esta obra está protegida bajo una Licencia Creative Commons Atribución-NoComercial 4.0 Internacional. 
los trabajos sobre sindicalismo de este periodo se centran en las protestas de profesores y ferrocarrileros, así como en las acciones de las centrales oficiales. Este trabajo fue construido, principalmente, con base en fuentes de primera mano.

Palabras clave: sindicato petrolero; sindicalismo; huelgas; desarrollo estabilizador; Adolfo Ruiz Cortines.

Abstract: The article seeks to reconstruct the mobilization of oil workers in 1958 and 1959, observe the demands and strategies of the struggle and lastly, to describe the government's tactics for maintaining control over this union. It documents the mobilizations of oil workers in Mexico City in 1958 and 1959, as well as their antecedents. It observes the causes and forms of the struggle and their association with other social sectors as well as the cooptation strategies implemented by the Mexican government. Accordingly, one can infer that oil workers received different treatment from the government from other movements. This, together with a negotiation strategy, enabled opposition leaders to join the official union system. All of the above took place within an environment of widespread social protest, led by unions affiliated to the government. The oil workers' movement during that period has not been studied. Papers on trade unionism at that time have tended to focus on the protests of teachers and railroader workers, as well as the actions of the official trade union centers. This paper was largely constructed on the basis of first-hand sources.

Key words: oil union; trade unions; strikes; stabilizing development; Adolfo Ruiz Cortines.

Fecha de recepción: 19 de abril de 2018 Fecha de aceptación: 27 de marzo de 2019

$E_{\text {q }}^{n}$ n la historiografía general del México contemporáneo se ha considerado que el periodo conocido como desarrollo estabilizador (comprendido por los sexenios de Adolfo Ruiz Cortines, Adolfo López Mateos y Gustavo Díaz Ordaz) se caracterizó por condiciones económicas favorables, las cuales habrían apuntalado un proceso de asentamiento político cuya expresión más clara sería el presidencialismo mexicano. 
A lo largo de estos años, se dio un crecimiento sostenido del producto interno bruto (PIB) de alrededor de 7\%, con inflación controlada. México mostró avances en su proceso de industrialización y, a favor de esta estrategia, el gobierno adoptó varias medidas proteccionistas a fin de sustituir las importaciones de productos elaborados y fortalecer la actividad interna. Vale señalar que en el ámbito internacional hubo otros países con crecimientos económicos similares, producto de instituciones y programas internacionales de reconstrucción de la economía (como serían el Banco Interamericano de Desarrollo o la Alianza para el Progreso), sobre todo después de la segunda guerra mundial, y de una mayor participación estatal en la economía. Por ejemplo, en México se crearon fideicomisos para impulsar la pesca, la producción de azúcar, el campo, la siderurgia y hasta la cultura, al tiempo que crecía la infraestructura en comunicaciones, en materia de salud y de educación con lo cual se pretendía otorgar algunos satisfactores sociales a la población.

Sin embargo, el estudio acucioso de estos años ha permitido señalar que se dieron algunas limitaciones en el desarrollo económico, en el control político y cierto coto al poder presidencial. En lo político, si bien es cierto que se reafirmó un intenso proceso de cooptación por parte del sistema (vía el Partido Revolucionario Institucional [PRI], los sindicatos y agrupaciones populares), este no siempre se llevó a cabo de manera puntual, ni por medio del consenso o la persuasión. Al surgimiento de cierta inconformidad contribuyó la contención salarial, el crecimiento de la población rural que migró masivamente a las ciudades en búsqueda de actividades laborales, un par de devaluaciones que generaron presión inflacionaria, pero también el autoritarismo del sistema político.

Uno de los mejores ejemplos de lo que se dice se encontró entre los años de 1958 y 1959, cuando se dio una amplia e intensa movilización de diversos sectores sociales. La prueba a la que fue sujeta el sistema no siempre fue superada de manera "limpia", pues en ocasiones las estrategias de mediación y control fracasaron, optándose entonces por soluciones de fuerza.

En estas coordenadas se ubica el presente trabajo, centrándose en las movilizaciones que llevaron a cabo los trabajadores petroleros (especialmente los pertenecientes a las secciones 34 y 35, asentadas en la ciudad de México), enmarcadas por un ambiente de protesta generalizada que, por momentos, pareció sofocar a las autoridades. Asimismo, se pretenden observar las demandas y estrategias de lucha sindical, así como las tácticas del gobierno para mantener el control. 


\section{EL SINDICALISMO PETROLERO, UN TEMA CASI OLVIDADO}

Entre las investigaciones realizadas en la historiografía nacional, relacionadas con los trabajadores petroleros encontramos, relativamente, poca información. Por una parte hay algunos textos de carácter testimonial como Valdivieso (1963) o Chávez Padrón (1988), otro tanto aparece inserto en series y colecciones consagradas a estudiar el movimiento obrero o en historias generales que abordan tangencialmente el tema de los trabajadores y los sindicatos. ${ }^{1}$

Por otra parte, cuando se han realizado estudios específicos sobre los petroleros, generalmente estos se concentran en los orígenes de dicha agrupación, como en Bravo, Rendón y González (1997) y Herrera (1998), o en periodos más recientes como Aguilar (1986) y Moreno (2007); algunas tesis también recorren esta misma temporalidad, entre otras Canales (1979), Pérez (1982), Hernández (1991) y Samgrae (1994); al igual que varios trabajos de carácter periodístico, por ejemplo Corro (1989), quedando un amplio vacío explicativo ante la ausencia de trabajos específicos sobre el sindicato petrolero en distintas temporalidades. Por ello las movilizaciones de los trabajadores petroleros que se dieron en la ciudad de México en el año de 1958 y que concluyeron en 1959 son, no obstante su importancia, una asignatura pendiente.

En ese sentido, la presente investigación pretende abonar al estudio de los conflictos laborales en el marco de la historia política nacional. Se centra en dos líneas de trabajo: la primera se refiere a la reconstrucción de las luchas de este gremio, sus causas y desarrollo en ese momento de la historia nacional, mientras que la segunda concierne a las formas de control ejercidas por el gobierno, partiendo de la hipótesis de que, en el caso de los petroleros, el gobierno aplicó formas de mediatización y control que fueron distintas a las utilizadas en otras movilizaciones que se dieron en condiciones similares en ese mismo momento.

Para la realización de este trabajo se ha decidido recurrir a fuentes primarias, dada la ausencia de textos explicativos de estos eventos. Se procederá a la reconstrucción de las movilizaciones estableciendo dos marcos referen-

${ }^{1}$ Encontramos obras colectivas como, La clase obrera en la historia de México, publicada por la Editorial Siglo XXI, que en varios volúmenes aborda el tema en cuestión. Asimismo, hay referencias amplias al movimiento obrero en la colección Historia de la revolución mexicana, publicada por El Colegio de México. Ambas colecciones se citan ampliamente en este texto. 
ciales: primero, el de los propios movimientos de petroleros hasta los años aquí tratados y, segundo, el contexto de movilización general que imperaba en los años 1958 y 1959. Por otra parte, se analizarán las formas de control ensayados por distintas instancias gubernamentales.

\section{ANTECEDENTES Y ENTORNOS DE LA MOVILIZACIÓN PETROLERA}

En la movilización de petroleros hubo dos vectores que la impulsaron. Uno fue cierto contexto de efervescencia social que se dio en el país y, el segundo, una dinámica propia de las luchas de los petroleros, particularmente en las secciones 34 y 35 . En cuanto al primero debemos considerar que, entre 1954 y 1970, México creció de manera importante en su economía dándose una intensa participación del Estado como promotor de la economía; así, la inversión pública creció, en particular en el rubro manufacturero (Tello, 2007, pp. 357 y ss.). Desde luego el desarrollo del proceso de industrialización en México tuvo como gran impulso una serie de acciones económicas (creación de infraestructura, financiamiento, legislaciones propiciatorias, etc.) así como políticas (control de las demandas de orden social) emanadas del Estado. ${ }^{2}$

Sin embargo, desde el gobierno de Manuel Ávila Camacho se dio una política de contención salarial debido, en parte, al contexto internacional de la segunda guerra mundial. La situación pareció estancarse durante el sexenio de Adolfo Ruiz Cortines, en particular a partir de abril de 1954 cuando se efectuó una devaluación del peso ante el dólar estadunidense pasando de 8.65 a 12.50 pesos por dólar. Esta medida, aunque respondía a una estrategia de protección a la producción nacional, en el corto plazo significó el aumento en los precios de productos y servicios impactando el nivel de vida de amplios sectores de la sociedad; se calcula que el costo de la vida aumentó 30\%. Este cuadro y la disminución -en términos reales- del salario se convertirían muy pronto en motivo de molestia en amplios sectores de asalariados y trabajadores. No obstante, el sindicalismo oficial logró contener la inconformidad, aunque no sería por mucho tiempo (Pellicer y Reyna, 1981, pp. 83-110).

${ }^{2}$ Womack (2007) señala: "La originalidad de la situación latinoamericana en relación con la prevaleciente en Estados Unidos o Europa en una época similar de su historia, es que la expansión capitalista se dio dentro de un marco político corporativo estatal” (p. 29). 
Para ello, el accionar del gobierno mexicano se vertió en dos sentidos: alzas salariales controladas y el otorgamiento de prestaciones. En el primer caso las revisiones siempre estuvieron supeditadas a la situación económica. En el segundo, y a manera de compensación, se dieron la entrega de estímulos económicos y la ampliación del sistema educativo. Ello selló un vínculo con el gobierno propiciando también algún inmovilismo. ${ }^{3}$

No obstante, hubo grupos de trabajadores que siguieron realizando demandas económicas y políticas. Para estos se aplicaron un par de estrategias distintas: la primera basada en la manipulación sindical, mediante una amplia burocracia de líderes subordinados al gobierno a través de las centrales y federaciones. En este plano los sindicatos y sus dirigentes dejaron de ser representantes del trabajador, para convertirse en agente mediatizador del Estado. Por si ello no fuera efectivo había un segundo recurso, el del uso de la fuerza. Los ejemplos fueron muchos entre 1958 y 1959, la movilización de los maestros de primaria sería emblemática por su persistencia, pues un primer brote de protesta se dio en 1956 por mejores salarios. Para 1958 las demandas no habían sido plenamente satisfechas y ello conduciría a la huelga, sólo que ahora se añadiría el reclamo de la legitimación de la dirigencia del sindicato. Otro tanto se daba con el sindicato de ferrocarrileros con peticiones de aumento salarial que derivaron en demandas de representación sindical, de tal forma la movilización, que encabezaba Demetrio Vallejo, logró poner en jaque a las autoridades. ${ }^{4}$ Estos fueron los movimientos más notorios de ese momento, su fuerza y estridencia explican que hayan sido ampliamente estudiados, sin embargo no fueron los únicos.

Por ejemplo, los pilotos aviadores afiliados a la Asociación Sindical de Pilotos Aviadores (ASPA), protestaron contra las arbitrariedades de las compañías de aviación comerciales y por el derecho a organizarse de manera independiente (Pozas, 2015, pp. 388-389)..$^{5}$ Por su parte, el Sindicato de Telefonistas de la República Mexicana (STRM) inició un "Movimiento restaurador"

${ }^{3}$ Womack (2007) lo visualiza así: "Es importante subrayar el peso que el Estado ejerció en la puesta en marcha y en la implementación del proyecto de la industrialización sustitutiva y en la construcción del marco institucional que le dio sentido y que permitió la participación de los trabajadores organizados en la estructura de poder. El Estado desempeñó un papel importante como empresario al impulsar inversiones cuantiosas" (p. 25).

${ }^{4}$ En torno al movimiento de los ferrocarrileros y las estrategias del charrismo sindical, véase Norman Caulfield (1998, pp. 106-120).

5 "Los pilotos aviadores a la opinión pública", El Universal, 22 de enero de 1959, desplegado firmado por el secretario general Andrés Fabre Tirán, donde solicitaba prestaciones como 
que pugnaba por aumentos salariales, la democratización del sindicato y la reinstalación de compañeros despedidos. Los telegrafistas buscaron crear un sindicato independiente del oficioso Sindicato Nacional de Trabajadores de la Secretaría de Comunicaciones y Transportes (SNTSCT). Por motivos salariales hubo movilizaciones como la del Sindicato de Electricistas, el Sindicato de Panaderos de la Ciudad de México y hasta los monosabios de la plaza de toros. Incluso sectores de estudiantes de la UNAM y del Politécnico se manifestaron en contra de las alzas en los pasajes del transporte público.

Otro elemento político a considerar era la sucesión presidencial. El candidato oficial sería el licenciado Adolfo López Mateos, titular de la Secretaría del Trabajo, precisamente quien había tratado en los años recientes con las problemáticas laborales. Tenía fama de ser buen mediador y conciliador pues hasta entonces, el ámbito laboral había permanecido dentro del cauce oficial; sin embargo, al final del sexenio la situación había cambiado radicalmente.

El "destape" de López Mateos sería en el mes de febrero y desde luego se buscó el apoyo de los sectores del PRI, la unidad a ultranza y la anulación de la disidencia. ${ }^{6}$ Por ningún motivo se quería otra experiencia como la campaña presidencial del general Miguel Henríquez Guzmán que había logrado cuestionar el sistema político. En esta ocasión se pretendía que el apoyo de las centrales obreras oficiales fuera unánime y dentro de ellas los petroleros. De tal forma el candidato hizo un mitin frente a la refinería de Azcapotzalco en el que participó el secretario general del sindicato, Felipe Mortera, y el Comité Ejecutivo Nacional (CEN) del sindicato.

Ruiz Cortines, por su parte, ante la inminencia de las elecciones presidenciales intentó resolver las peticiones económicas; sin embargo, el espectro de las demandas se multiplicó, pues rápidamente estos movimientos derivaron en exigencias de orden político.

fondo de retiro. Por su parte los telegrafistas habrían formado la Alianza de Telegrafistas, liderados por Ismael Villavicencio.

${ }^{6}$ Como un mensaje cifrado, con anterioridad habían aparecido carteles en la refinería de Azcapotzalco, criticando las elecciones de 1952 que había llevado a Ruiz Cortines al poder. En los pasillos sindicales se culpaba de ello a Juan Ortega Arenas, a Miguel e Ignacio Hernández Alcalá. Dirección Federal de Seguridad. Versión Pública de Felipe Mortera. 12 de septiembre de 1957. Caja 305, f. 49. Archivo General de la Nación (en adelante AGN), México. 


\section{LA DINÁMICA PETROLERA}

A partir de la formación del Sindicato de Trabajadores Petroleros de la República Mexicana (sTPRM), en 1935, la elaboración de un contrato colectivo y su cumplimiento habría sido la demanda central, al punto que, en 1938, daría pauta a la expropiación. Paradójicamente, a pesar del surgimiento de la empresa nacional Petróleos Mexicanos (PEMEX), no se redactó un contrato, sino que se emitió un laudo que, de acuerdo con las protestas del sindicato, no se cumplía.

Ello sería motivo de protesta, paros, y hasta huelgas en los años subsecuentes. Por ejemplo, hacia 1939 la solicitud de tener un contrato colectivo de trabajo sería la principal causa, aunque no la única, de movilización de los petroleros ante el gobierno de Lázaro Cárdenas y, posteriormente, ante el de Manuel Ávila Camacho. ${ }^{7} \mathrm{Al}$ respecto, las posiciones llegaron a ser completamente opuestas pues, mientras el sindicato refería que sus agremiados vivían en peores condiciones que antes de la expropiación, la empresa replicaba que, en realidad, los petroleros eran un sector privilegiado que ganaba mucho más que antes y que otros grupos de trabajadores cuestionándose, de paso, el patriotismo de este gremio. Así, en el periodo de Ávila Camacho las demandas de mejores condiciones laborales fueron una constante que ocasionaría graves problemas (Basurto, 1984).

La movilización constante del sindicato impulsó que, finalmente en mayo de 1942, se firmara un contrato colectivo por el secretario del Trabajo, Ignacio García Téllez, el director de Pemex, Efraín Buenrostro, y Antonio Salmón, secretario general del STPRM. ${ }^{8}$ En lo sucesivo la revisión del contrato colectivo sería el momento de mayor disputa entre sindicato y empresa. Las discusiones en torno a sus detalles y aplicación demostrarían que las relaciones laborales no habían cambiado radicalmente. La sustitución de los antiguos dueños extranjeros por una empresa con sentido nacional no alteró las relaciones típicas de patrón y empleado. En todo caso se inauguraba un escenario novedoso y contradictorio, ya que tanto el sindicato (afiliado a la

${ }^{7}$ De acuerdo con Jonathan Brown (2000), el general Cárdenas habría tolerado los movimientos huelguísticos, mientras tuvieran el fin de fortalecer el movimiento sindicalista, pero una vez logrado ello se esperaba que hubiera disciplina con las directrices gubernamentales (p. 66).

8 "Primer contrato uniforme de la industria petrolera", El Nacional, 6 de mayo de 1942, p. 2. 
Confederación de Trabajadores de México [стм]) como la empresa, estaban adosados al gobierno.

Una enumeración sucinta de las fricciones por esta causa incluiría un paro en Poza Rica en agosto de 1943, para que se aprobara el contrato (Basurto, 1984, pp. 165 y ss.). También se dieron movilizaciones en la ciudad de México donde se limitó el suministro de combustible en febrero de $1944 .{ }^{9} \mathrm{Al}$ año siguiente el secretario general del STPRM, Isidoro Gutiérrez, notificó el emplazamiento a huelga para el 2 de abril acusando a la empresa de incumplir el contrato colectivo. ${ }^{10}$ El último año de gobierno de Ávila Camacho fue especialmente intenso pues hubo un paro del 16 al 17 de abril (Basurto, 1984, p. 173), en junio se dio un nuevo emplazamiento que se solventó de manera temporal, ${ }^{11}$ y continuó en las secciones de la capital en los meses subsecuentes, ${ }^{12}$ al punto que, en septiembre, la empresa determinó una suspensión de actividades para evitar la huelga y solicitar el resguardo de las instalaciones por las fuerzas federales.

Este activismo generó muchas molestias debido al desabasto de combustibles, así como una situación compleja con la стм, la cual se veía ineficaz para controlar a los petroleros que no parecían suscribir la idea del colaboracionismo con el gobierno de Ávila Camacho. Tal actitud habría propiciado la salida de los petroleros de la стм y no retornarían a esta central hasta diciembre de 1951 (Basurto, 1984, p. 178).

En este ambiente de confrontación se dio un nuevo paro en la refinería de Azcapotzalco de finales de 1946 hasta la toma de posesión del nuevo presidente, el licenciado Miguel Alemán. Ante ello el nuevo gobierno determinó la ocupación, por el ejército, de las refinerías de Tampico, Azcapotzalco y Minatitlán. De inmediato se dieron ceses, detenciones a los líderes y el planteamiento, ante la Junta de Conciliación y Arbitraje, del conflicto de orden económico, lo cual permitiría hacer nuevos ajustes en salarios y restricción de plazas (Basurto, 1984, pp. 183-185). Esto marcaría una política estatal de mayor control sobre el sindicalismo en general, el rechazo a la protesta, y el mensaje de que los métodos de control podrían incluir, en lo sucesivo, la fuerza y no sólo el acuerdo y la mediación (Medina, 1982, pp. 151-161).

\footnotetext{
9 Entre varias notas: "Resultó un golpe directo al público capitalino el paro petrolero", Excélsior, 28 de febrero de 1944.

${ }_{10}$ Novedades, 17 de marzo de 1945.

11 “Concluyó el paro en Pemex”, El Nacional, 27 de junio de 1946.

12 "Otra huelga petrolera", El Universal, 17 de agosto de 1946, p. 9.
} 


\section{PEMEX Y LOS PETROLEROS EN EL PERIODO DE ADOLFO RUIZ CORTINES}

Otro componente de estas movilizaciones sería la situación particular de PEMEX. Hacia el sexenio de Ruiz Cortines la empresa continuaba con la visión de propiciar el desarrollo industrial, lo cual había sido una tarea realizada desde los años de la expropiación, cuando la industria petrolera nacional estaba en declive. A partir de entonces, se desarrolló una estrategia que privilegió la exploración y la producción de crudo, que ascendió de 38400000 barriles en el año de la expropiación a 93500000 en 1958, más del triple. Otros indicadores que muestran el progreso en este ramo fueron el consumo interno y las exportaciones de crudo. Debido al creciente consumo de refinados se llevó a cabo de manera paralela un aumento en la construcción de refinerías. Claramente la estrategia de PEMEX se dirigió a fortalecer el mercado interno, tratando de disminuir las importaciones de gasolina, esto se observa en las estadísticas que muestran cómo se pasó de 102000 barriles refinados diarios en 1938 a 322000 en 1958 (Meyer y Morales, 1990, pp. 120-121). Como parte de esta estrategia se estimuló la producción de destilados y se controlaron los precios de gasolina, queroseno, diésel y gas licuado (p. 126).

Adicionalmente, hay que considerar que, en estos años, Pemex se convirtió en la principal fuente de ingresos para el erario, y si a ello aunamos la contención en los precios de los productos refinados, las devaluaciones de la moneda frente al dólar, y el aumento en la compra de insumos de producción en el extranjero, tendremos que, hacia finales del periodo de Ruiz Cortines, la empresa pasaba por un momento difícil. Habría que sumar que Pemex había multiplicado la contratación de trabajadores, pasando de 17600 entre la categoría de planta y transitorios a 45532 en ese periodo (Meyer y Morales, 1990, p. 140).

En esos años el propio director de Pemex, Antonio J. Bermúdez, señalaba las causas del estancamiento en varios puntos: 1) precios bajos y no remunerativos; 2) deterioro de la mística petrolera (refiriéndose a la falta de espíritu nacionalista, corrupción, favoritismo por las compañías de funcionarios); 3) distracción de recursos a otras actividades; 4) falta de labores de exploración; 5) endeudamiento, y 6) intromisión federal en el manejo de la empresa (Bermúdez, 1988, pp. 48-50).

Ello había generado desequilibrio de tal forma que, con el fin de sanear las finanzas petroleras, se habrían ideado varias estrategias como actualizar 
los precios de los productos elaborados por la empresa o emitir bonos de PeMEX para que se comercializaran en el mercado bursátil y significaran un ingreso adicional..$^{13}$ Asimismo, se ensayó la restricción de gastos que pasaba por recorte de personal, reducción de obras sociales e, incluso, la suspensión de aumentos salariales a los empleados.

A fin de que este plan tuviera éxito, se habría llegado a un acuerdo con la dirigencia del STPRM, entonces encabezada por Felipe Mortera, en el sentido de posponer la revisión del contrato colectivo, lo cual iba en contra de los intereses de los trabajadores, provocando la protesta particularmente de las secciones 34 y 35 (aunque no fueron las únicas).

Como se puede observar, estaban dados los elementos para la movilización de los petroleros: un ambiente de protesta generalizada, la tradición de militancia del STPRM, el estancamiento en las condiciones laborales y económicas de Pemex y del país. El escenario en donde se agudizarían estas circunstancias sería la ciudad de México, en donde estaban asentadas las oficinas centrales de Pemex (sección 34) y la refinería de Azcapotzalco (sección 35), y el momento sería el proceso de renovación de las dirigencias seccionales. ${ }^{14}$

La oposición era liderada por Nicéforo Pérez Cárdenas quien tenía antecedentes de oposición al sistema, se integró a la campaña presidencial de Henríquez Guzmán en 1952 y, para diciembre de ese año, se postuló para dirigir la sección 34 contando con el apoyo de varios correligionarios, entre ellos Ismael Hernández Alcalá y Mario Pavón Flores, quienes fungían como asesor y abogado de los trabajadores, respectivamente (Alzaga, 2007). El proceso fue confuso, lleno de irregularidades, de mucho activismo; de manera que, en el periodo de enero hasta el mes de septiembre de ese 1953, la sección 34 quedó acéfala, hasta que las autoridades de la Secretaría del Trabajo desconocieron a los inconformes.

Quedó claro desde entonces que la demanda de democracia sindical sería una causa central que iba en varios sentidos. Primero en el cuestionamiento a los procedimientos de elección interna en cada sección. Otro contra

13 "Primera compra de un millón de bonos Pemex", Excélsior, 4 de junio de 1958, p. 1. Este producto sería conocido como "bonos estabilizados", que de acuerdo con la prensa estadunidense permitirían capitalizar a la empresa; "Elogian a Pemex y a Carrillo en N. Y.", Excélsior, 12 de junio de 1958, p. 1.

${ }^{14}$ Para este asunto: Informe fechado en junio y julio de 1951. Fondo Dirección General de Investigaciones Políticas y Sociales. Caja 803, exp. 3. AGN, México. 
las formas de integración del CEN del sindicato, el cual en estos años ya aparecía como un instrumento de control hacia la base petrolera, subordinado a las líneas establecidas desde la стм y a los requerimientos administrativos de Pemex y de la Secretaría del Trabajo. ${ }^{15}$

Un ejemplo de protesta, entre muchos, fue el movimiento que se dio en las secciones de la ciudad de México en contra del secretario general, Ignacio Pacheco, por estar entregado a la empresa ${ }^{16}$ En ese esquema se consideraba que los líderes funcionaban como un dique de control burocrático ante los trabajadores y como un aliado de las autoridades y centrales obreras oficiales. Se desarrolló así la cultura de los líderes "charros" como parte de la estrategia de control político del Estado.

Desde luego que la antidemocracia sindical provocaría la protesta y el acercamiento a otras organizaciones sindicales y sectores sociales, sobre todo a partir del golpe a los trabajadores de la refinería de Azcapotzalco en diciembre de 1946 y el llamado "charrazo" de $1948 .{ }^{17}$ Entonces el gobierno mexicano se esforzó por tener el control sobre el sindicato, hacer que se reintegrara a las huestes de la Стм y erradicar la presencia de los comunistas. ${ }^{18}$

Desde el punto de vista ideológico y de desempeño político, el sindicato petrolero había conservado bastante independencia hasta el momento de la expropiación; es claro que a partir de entonces se estrecharía su vínculo con el Estado mexicano que, en los años sucesivos, trató de limitar el activismo y demandas de los petroleros -y de otros sindicatos-a través de la política corporativa implementada por medio de la Стм y del partido oficial. ${ }^{19}$ Es claro que la integración de la CTM al PRI establecía una conexión entre el movi-

${ }^{15}$ Fueron muy comunes los casos de lucha por el control sindical, al respecto puede consultarse, sólo como muestra. Fondo Adolfo Ruiz Cortines. Exps. 437.3/15; 432/95 y 432.3/18. AGN, México.

${ }^{16}$ En relación con el movimiento de 1954, liderado por Juan Ortega Arenas y Nicéforo Pérez Cárdenas. Fondo Adolfo Ruiz Cortines. Exp. 437.3/9, leg. 2. AGN, México.

${ }_{17}$ De hecho, en el año de 1947, varios sindicatos nacionales de empresas y servicios otorgados por el Estado como ferrocarrileros, mineros y petroleros, salieron de las filas de la Confederación de Trabajadores de México (стм), por considerar que esta central no representaba plenamente sus intereses, insertándose en la Central Única de Trabajadores (сUT).

${ }_{18}$ Al respecto, véase Barbosa Cano (1979, pp. 246-260). De acuerdo con Norman Caulfield (1998, pp. 102-103) esta estrategia se realizaba con la participación de la Organización Regional Interamericana de Trabajadores (ORIT) y el gobierno de Estados Unidos.

${ }^{19}$ Juan Felipe Leal (1976) comenta: "Al ser enclavados los sindicatos en grandes centrales obreras y al pasar estas a formar parte del partido del Estado, los sindicatos se convirtieron en organismos de orden público. Con ello quedó establecida la cadena de dominación Estado-parti- 
miento obrero y el gobierno, ello permitía la obtención de canonjías (sobre todo para los líderes), programas sociales, acuerdos salariales y prestaciones. Pero esto también implicaba -lo que era central- su sujeción al gobierno y a sus políticas de desarrollo económico y control político. ${ }^{20}$ En resumen, significaba que la independencia ideológica que se había mantenido hasta entonces se vería truncada, dando paso a la subordinación del movimiento obrero en sus luchas y en sus demandas. ${ }^{21}$ En lo sucesivo los asomos de comunismo serían limitados, perseguidos y erradicados del STPRM.

Por otra parte, vale considerar que buena parte de la movilización que se había dado hasta finales de los años cuarenta había sido alentada por el propio gobierno en su proyecto nacionalizador. En los años sucesivos, los sindicatos de industria se quedarían sin la bandera de lucha contra el imperialismo y sin el apoyo incondicional del Estado, que ahora asumía las funciones de patrón. ${ }^{22}$

Por otra parte, el activismo y la posible vinculación de los petroleros a otros sindicatos y a otras corrientes políticas causó alarma en el gobierno. Un ejemplo de esto fue el apoyo de las secciones 34 y 35 a los ferrocarrileros en las movilizaciones que llevaron a cabo desde 1954, a los maestros desde 1956, o bien su vinculación con los henriquistas en 1952. En torno a esto último, la candidatura del general Miguel Henríquez Guzmán funcionó como catalizador de la inconformidad con el sistema, en la que se insertaron sectores de ferrocarrileros, mineros y petroleros. Otro tanto se temía por la militancia de petroleros en el Partido Obrero Campesino Mexicano y en el Partido Comunista lo cual, en el contexto de la guerra fría, mantenía en alerta al gobierno mexicano otorgando un excelente argumento a los líderes de la стм para descalificar movimientos cuyas demandas excedieran lo estrictamente económico. ${ }^{23}$

do-sindicato y se sentaron las condiciones para que dentro de las organizaciones gremiales cristalizara una burocracia sindical representante del Estado dentro del movimiento obrero" (p. 46).

${ }^{20}$ Leal (1976) señala: "Al participar los sindicatos -directo o indirectamente- en la legislación y en la reglamentación, son colocados dentro de la esfera política propia del Estado. Estos se convierten en organismos de orden público, en aparatos constitutivos del Estado" (p. 123).

${ }^{21}$ Womack (2007) señala en este sentido: "la política sindical tendió a fortalecer los partidos políticos que canalizaron esas reivindicaciones hacia las instancias de poder. Los sindicatos buscaron nexos con dichos partidos a través de que sus líderes participaron en ellos. En un caso, los partidos eran sólo correas de transmisión, que actuaban de acuerdo con plataformas ideológicas, externas al sindicalismo, que eran impuestas sobre los trabajadores" (p. 15).

${ }^{22}$ Al respecto, véase Zapata (1993, pp. 129-140).

${ }^{23}$ Una revisión del archivo Centro de Estudios del Movimiento Obrero y Socialista (en adelante CEMos), muestra que en efecto había células del Partido Comunista insertas en las secciones 34 y 35 del STPRM. Sin embargo, es dudosa la influencia que podían ejercer. Para 


\section{LOS MOTIVOS DE MAYO}

Con los antecedentes y contexto ya señalados, no sería de extrañarse que los petroleros se movilizaran, sólo se necesitaba un buen motivo. Así, en mayo de 1958, la dirigencia del STPRM, encabezada por el secretario nacional, Felipe Mortera Prieto, acordaría con la dirección de Pemex la posposición por catorce meses de la revisión del contrato colectivo, bajo el argumento de la compleja situación económica de la empresa. Tal determinación significaba que los trabajadores no recibirían un aumento salarial y que se nulificarían compensaciones como servicio médico, jubilaciones, etc., lo que generó mucha molestia en varias secciones, aunque la 34 y la 35 tomaron la vanguardia de la protesta.

En la sección 35 se dio un inmediato rechazo a tal disposición provocándose manifestaciones y peleas desde el 18 de mayo, encabezadas por los hermanos Hernández Alcalá (conocidos como los "Chimales"), Nicéforo Pérez, Pedro Durán Zumaya, y otros más. ${ }^{24}$ También la sección 1, con cabecera en ciudad Madero, se sumó a la protesta. No obstante, la posición de la dirigencia nacional fue en el sentido de demostrar la unidad de las 25 secciones que conformaban el sindicato y de exhibir a los inconformes como comunistas y agitadores profesionales, a quienes se podría aplicar la cláusula de expulsión. ${ }^{25}$

ello consúltese el Fondo Partido Comunista Mexicano Locales. Exp. Solicitudes de ingreso. Promoción J. Guadalupe Rodríguez. Caja en proceso. CEMos, México. En este que se señala la presencia de trabajadores petroleros, ninguno de ellos era del grupo de los líderes. En estos años había dos células, una era la "18 de Marzo" y la otra "Refinería", que tenía miembro en algunas secciones, por ejemplo, en ciudad Madero había otro grupo más llamado "Petroleros", véase Partido Comunista Mexicano Locales. Expediente Tamaulipas, años 1957-1958. CEMos, México; Partido Comunista Mexicano Locales. Exp. "Estadísticas de miembros del PCM". Caja en proceso, también en caja 32, exp. 11 y exp. 12. cemos, México. Más adelante, hacia 1967, un informe señalaba la presencia, en la sección 35, de la célula "Comuna de París", que estaba afiliada a la Liga Comunista Espartaco, la cual se planteaba la lucha contra el charrismo sindical, las miserables condiciones de vida, la explotación, el capitalismo y por la revolución socialista. Dirección General de Investigaciones Políticas y Sociales. Caja 455, exp. 2, f. 713. AGN, México.

${ }^{24}$ Véase la nota "Purga sindical por disolución social", Excélsior, 19 de mayo de 1958, p. 1.

25 "Se han unificado los petroleros", Excélsior, 23 de mayo de 1958, p. 1. Desde luego en la versión oficial los petroleros se decían manipulados por los hermanos Hernández Alcalá, y disciplinadamente aceptaban la prórroga en la revisión del contrato colectivo y, en consecuencia, apoyaban al Comité Ejecutivo Nacional. Al respecto véase también, "Acaba la agitación entre petroleros", El Universal, 19 de mayo de 1958, p. 1. 


\section{JULIO}

Al parecer obligado por las presiones de los trabajadores, el día 11 de julio se dio una reunión entre sindicato y empresa. En ese momento, un grupo de alrededor de 500 trabajadores, encabezados por Carlos Castillo, Raúl Ibarra, los "Chimales", y otros líderes más, apoyados por contingentes de ferrocarrileros, telegrafistas, maestros y electricistas, penetraron al recinto del STPRM, sacaron a Antonio Ardilla, al momento secretario general de la sección 34, presionaron a Felipe Mortera y forzaron a que se formara una comisión especial que incluyera a los inconformes, para tratar el asunto del contrato colectivo. Asimismo, hubo una concentración ante el edificio de Pemex. Ante tal escenario la dirigencia se vio forzada a entablar una nueva negociación con la empresa. ${ }^{26}$

Las reuniones duraron seis días continuos hasta que se aceptó otorgar un aumento mensual de 210.57 pesos por trabajador y más de $30 \%$ en el fondo de ahorros.$^{27} \mathrm{El}$ resultado era, indudablemente, un triunfo para los trabajadores y para los disidentes quienes habían impulsado la protesta, por lo menos esa era la percepción generalizada.

No obstante el logro, los demandantes dieron un giro y los reclamos se desbordaron hacia el tema de la representación sindical. Surgió entonces la petición de deponer de la secretaría nacional a Felipe Mortera y a los líderes oficiales de las secciones 34 y 35 . Como ya se ha visto en casos anteriores las demandas de orden económico iban seguidas, de manera inmediata, por las de orden político: elecciones y dirigencias representativas. Esta no fue la excepción y el 19 de julio se forzó a una nueva votación en ambas secciones, obteniendo el triunfo el "Movimiento Depurador Sindical".

Entonces el líder "oficial" de la sección 35, Antonio Ardilla Fonrouge, denunció que los comunistas trataban de apoderarse de la sección a través de los hermanos Hernández Alcalá quienes estaban en sociedad con Agustín

26 "Pemex negocia con sus obreros para mejorarlos sin dañar la industria", Excélsior, 12 de julio de 1958, p. 1. Un informe detallado se encuentra en Dirección Federal de Seguridad. Versión Pública de Felipe Mortera. Caja 305, fs. 70-72. AGN, México.

27 "Anoche se resolvió el conflicto planteado a Petróleos Mexicanos por sus trabajadores", Excélsior, 17 de julio de 1958, p. 1; “Están conformes los petroleros con el aumento", Excélsior, 18 de julio de 1958, p. 1. 
Sánchez Delint (líder de los electricistas), Demetrio Vallejo (líder ferrocarrilero) y Othón Salazar (líder del magisterio). ${ }^{28}$

\section{LOS RELÁMPAGOS DE AGOSTO}

Para el mes de agosto la exigencia de tener una representación auténtica había escalado. Se demandó la revisión de los comicios fraudulentos, se rechazó el intervencionismo del subsecretario del trabajo, Salomón González Blanco, y del secretario nacional del sindicato, Felipe Mortera. ${ }^{29}$ Claramente el acento de las demandas había pasado a lo político. Aún más, el movimiento se estaba potenciando con el apoyo de otras agrupaciones como del sindicato de ferrocarrileros, de maestros, los telegrafistas, electricistas, y estudiantes universitarios. Asimismo de la Federación Revolucionaria de Obreros Textiles, la Confederación de Campesinos, la CROc y la CRT. ${ }^{30}$

Más adelante estas acciones darían la pauta para formar el Movimiento Depurador 27 de Agosto, pues ese día, 70 de los inconformes se apostaron a las afueras del edificio de Pemex e iniciaron una huelga de hambre demandando que se reconocieran como secretarios generales a Carlos Castillo en la sección 34 y a Ismael Hernández en la 35. Los líderes contaban, indiscutiblemente, con gran apoyo dentro y fuera de sus secciones, lo cual significaba que el movimiento podía expandirse. La estrategia seguida por las autoridades se ciñó a la pauta seguida por otros gremios, es decir la represión; no obstante, los petroleros resistieron y lograron entrevistarse con el director de la empresa, Antonio J. Bermúdez, a quien solicitaron repetir la elección. ${ }^{31}$

${ }^{28}$ Adolfo Ruiz Cortines. Exp. 437.3/8, leg. 3. AGN, México. En este expediente se incluyen varios telegramas dirigidos a las autoridades, en apoyo a los líderes independientes. Estos telegramas eran de trabajadores a título personal, y ciertamente no de los líderes de las diversas secciones.

29 “Piden se dé posesión a dos líderes petroleros", El Popular, 24 de agosto de 1958, p. 1. También puede consultarse en Dirección Federal de Seguridad. Versión Pública de Ismael Hernández Alcalá del 23 de agosto, 1958, fs. 26-27. AGN, México.

30 "Huelga de hambre sí, pero cómodos", El Universal, 28 de agosto de 1958; "70 petroleros iniciaron su huelga de hambre y 500 más ofrecen secundar”, Excélsior, 28 de agosto de 1958, p. 1.

31 "Gobernación y trabajo, en la solución del caso petrolero y Bermúdez no interviene en el caso intergremial", El Popular, 29 de agosto de 1958, p. 1. Desde luego la versión oficiosa era distinta, de acuerdo con ella los agresores habían sido los trabajadores petroleros y las víctimas los granaderos. "Penoso incidente con los policías", El Nacional, 29 de agosto de 1958, p. 1. Se encuentran narraciones extensas y complementarias, con algunos detalles del incidente: "Ga- 
El día 29 las negociaciones continuaron bajo un clima de extrema tensión pues los petroleros intentaron realizar un nuevo mitin, el cual les fue impedido. Sin embargo, contaron con el apoyo de sectores de estudiantes de la unAm y del Politécnico que por su cuenta se habían movilizado demandando pasajes de transporte más baratos. ${ }^{32}$ Se dio entonces un violento enfrentamiento, ferrocarrileros, estudiantes y otros trabajadores se reagruparon y armaron con piedras y palos para resistir el embate de la policía. En la refriega varios automóviles fueron incendiados. Al final hubo más de quince detenidos y la certeza de que los petroleros no cederían fácilmente a la imposición. ${ }^{33}$

En el gobierno federal existía la posición inicial de sólo reconocer a los líderes afectos a la dirigencia nacional y, en consecuencia, subordinadas a las líneas gubernamentales. Sin embargo, debido al encono de la protesta, las autoridades ensayaron proyectar una imagen de neutralidad ante un conflicto al que se trató de dar un cariz exclusivamente intragremial. ${ }^{34}$ Por su parte, la dirigencia nacional del sindicato, en voz de Felipe Mortera, rechazó con firmeza los intentos de los grupos disidentes. Se arguyó que el reglamento del sindicato no posibilitaba una nueva elección, se decían mayoritarios en las secciones en conflicto y amenazaban con sancionar a los inconformes.

Desde las esferas del sindicalismo oficial, encarnado por Fidel Velázquez, se descalificó a los inconformes bajo el argumento de que todas las movilizaciones (incluidos ferrocarrileros, maestros y petroleros) eran parte de un plan desestabilizador del movimiento obrero. Desde luego se imponía la teoría de la conjura comunista:

En algunas agrupaciones del Bloque de Unidad Obrera priva la impresión de que los comunistas, como de costumbre, han metido la mano en esta agitación. Se basa esta impresión en los antecedentes de algunos de los dirigentes de los últimos movimientos. En el caso de los petroleros, que es el que ahora se confronta, los hermanos Hernández Alcalá son de clara filiación comunista.

ses lacrimógenos contra los huelguistas", Excélsior, 29 de agosto de 1958, p. 1; "La policía obligó a desalojar el edificio principal de Pemex”, El Universal, 29 de agosto de 1958, p. 1.

${ }^{32}$ "La Secretaría del Trabajo impondrá la ley en el conflicto intergremial de petroleros", El Nacional, 30 de agosto de 1958, p. 1.

33 "Continúa el conflicto petrolero, después de la gresca de ayer", Excélsior, 30 de agosto de 1958, p. 1; "Violentos choques en el centro de la ciudad", El Popular, 30 de agosto de 1958, p. 1.

34 "Las elecciones de petroleros, fuera de los estatutos", Excélsior, 30 de agosto de 1958, p. 1. 
Desde 1946 en que encabezaron un movimiento contra el gobierno del licenciado Alemán y que aplacaron las fuerzas federales, siempre han estado tratando de agitar para que comunistas manejen esta industria básica del país. ${ }^{35}$

Finalmente, el 30 de agosto se destrabaron las negociaciones, los representantes del STPRM y los de la Secretaría de Gobernación, presionados por la escalada de violencia, se vieron forzados a admitir que se realizaran nuevas elecciones en las secciones 34 y 35, pactado ello para el 17 de septiembre mediante un convenio de diez puntos que regulaba la forma en que se realizaría la nueva votación. Ello en sí constituía una nueva victoria para los dirigentes independientes. No hay que perder de vista que era ya la víspera del último informe del presidente Ruiz Cortines y no era deseable un escenario de inestabilidad en este último gran acto público, su despedida de la nación. ${ }^{36}$

\section{DURANTE EL MES DE LA PATRIA}

Después de los acuerdos con los trabajadores, se efectuó el rito anual del informe de gobierno; las expresiones "espontáneas" de admiración y agradecimiento se constataron en la valla que formaron 300000 trabajadores que resguardaron el paso del presidente. En torno al Bloque de Unidad Obrera (BUO) (que constituía al momento la central de centrales) se organizaron par-

35 "Intereses bastardos se mueven en la agitación de petroleros", El Universal, 30 de agosto de 1958 , p. 1. Esta idea era parte de un ambiente propio de los llamados años de la guerra fría, y estaba bien acendrado en el sistema político mexicano. Es importante señalar que en las esferas gubernamentales la paranoia contra el comunismo era generalizada, ilustrativo de ello es lo señalado por Antonio Ortiz Mena (1998), el secretario de Hacienda: "Durante 1958 México fue objeto de un importante intento de desestabilización encabezado por el Partido Comunista Mexicano. Durante ese año ocurrieron 740 huelgas, número muy superior a las 150 que en promedio habían estallado durante los cinco años anteriores. Los principales movimientos desestabilizadores tuvieron una fuerte injerencia de dicho partido, como fueron los casos de telegrafistas, maestros, ferrocarrileros y petroleros" (p. 76).

${ }_{36}$ Véase "Acuerdos para las elecciones de trabajadores petroleros", El Popular, 31 de agosto de 1958, p. 1, ahí se puede constatar la intervención del mismo presidente de la república, de acuerdo con declaración de Ismael Hernández Alcalá. También se desprende ello del encabezado de la nota: "Patrióticas soluciones presidenciales a los problemas de estudiantes y de petroleros", El Nacional, 31 de agosto de 1958, p. 1. Véase también, "Fueron fijadas para el 17 de septiembre", Excélsior, 31 de agosto de 1958, p. 1; "El conflicto petrolero", El Universal, 31 de agosto de 1958, p. 1; "Elección de petroleros el día 17", El Popular, 14 de septiembre de 1958, p. 1. 
celas del recorrido. Así, segmentos eran cubiertos por la CTM, la CROM, la CGT, y por los afiliados a la CROC (que no era integrante del BUO). Los periódicos reprodujeron, en grandes desplegados pagados, consignas que reiteraban lealtad de las centrales y sindicatos oficiales, descalificando el "oportunismo" de ciertos grupos que habían aprovechado la coyuntura electoral y el final del gobierno de Ruiz Cortines para obtener algún beneficio.

Desde luego estas demostraciones de apoyo, aunque inducidas por las centrales, también representaban parte de una realidad innegable: la del acuerdo y subordinación de una buena parte del sector obrero a las líneas políticas y económicas del Estado. Sin embargo, algo que quedaba fuera de este montaje era el ambiente de franca confrontación con otros sectores que, paradójicamente, se daba entre los sindicatos de trabajadores al servicio del propio Estado mexicano: ferrocarrileros, maestros, y ahora los petroleros.

Como estaba previsto, el día 17 se efectuaron las elecciones de las secciones 34 y 35 ante representantes de las Secretarías de Gobernación y del Trabajo, al tiempo que un grupo nutrido de granaderos se apostaba en las cercanías de las sedes electorales. En la sección 34 contendieron Carlos Castillo, del grupo independiente de los "Chimales", y Fernando Labastida, adosado a Felipe Mortera. En este caso la victoria fue más que clara para Castillo, quien obtuvo 940 votos contra 70 de su oponente. En la sección 35 la victoria también fue contundente para el independiente Ignacio Hernández Alcalá, quien obtuvo 464 votos contra los apenas 205 del candidato "oficial" Antonio Ardila. Un triunfo total de los opositores al oficialismo sindical de los petroleros. ${ }^{37}$

Entonces, Ignacio Hernández Alcalá se propuso un plan de trabajo que incluía auspiciar el movimiento depurador de líderes deshonestos a escala nacional. Al mismo tiempo se planteó como estrategia buscar un acercamiento con las autoridades federales, tratando de rebasar las trabas que implicaban la dirigencia de Mortera. Por ello, invitó al presidente Ruiz Cortines a que asistiera a una asamblea de la sección 34 con la idea de mostrar que se trataba de un movimiento pacífico y de generar una interlocución directa. ${ }^{38}$

37 Véanse diversas notas: "El grupo de los 'Chimales' ganó mayoría en el recuento", El Popular, 18 de septiembre de 1958, p. 1; “Triunfaron los 'Chimales”, Excélsior, 18 de septiembre de 1958, p. 1; "Reconocimiento a los 'Chimales”, Excélsior, 18 de septiembre de 1958, p. 1.

38 Véase el telegrama de Ignacio Hernández Alcalá al presidente Adolfo Ruiz Cortines. 18 de noviembre de 1958. Fondo Adolfo Ruiz Cortines. Leg. 3, exp. 437.3/8. AGN, México. 


\section{AGITADO FIN DE AÑO}

No obstante la clara victoria, continuaron las dificultades, por lo cual se efectuó un paro el 10 de noviembre en la refinería de Azcapotzalco, convocado por la dirigencia de la sección 35, para que se procediera a la expulsión de un grupo de choque vinculado a la dirigencia nacional, que trataba de generar alarma y descalificación hacia los independientes, señalando supuestos actos de sabotaje. ${ }^{39}$

Ello daría el pretexto ideal para que la dirigencia seccional fuera consignada ante el Consejo General de Vigilancia del STPRM, pidiendo su expulsión e iniciando una averiguación ante la Procuraduría General de la República (PGR). ${ }^{40}$ Finalmente, los representantes de la sección 35 fueron suspendidos en sus derechos el día 22 de ese mes. ${ }^{41}$

El 1 de diciembre asumió la presidencia de la república el licenciado Adolfo López Mateos, quien nombró a Salomón González Blanco como secretario de Gobernación y al ingeniero Pascual Gutiérrez como director de Pemex. Esto al tiempo que se organizaba la Asamblea Nacional del STPRM de la cual saldría una nueva dirigencia. Estas designaciones implicaron tanto un replanteamiento en los objetivos de Pemex como en la relación con sus trabajadores. En cuanto a lo primero se inició un proceso de ordenamiento económico de la empresa, que incluía alzas en el precio de los combustibles, recortes de gasto e, incluso, la privatización de ciertas áreas como la petroquímica. En cuanto a las relaciones laborales y contractuales, se procedió a centralizar el poder sindical y el control de las secciones insumisas. ${ }^{42}$ En esas circunstancias, los pocos meses que corrieron desde las elecciones de septiembre hasta la asamblea nacional del STPRM, el camino estuvo lleno de escollos para los "chimales" y seguidores.

${ }^{39}$ Véanse "Que intentaban incendiar la refinería", Excélsior, 18 de septiembre de 1958, p. 1, y "Discuten el caso de los 'Chimales", Excélsior, 18 de septiembre de 1958, p. 1.

${ }^{40}$ Véanse "Se presentarán los 'Chimales”, Excélsior, 16 de septiembre de 1958, y “Negaron la suspensión a los “Chimales”, El Popular, 16 de septiembre de 1958.

${ }^{41}$ Dirección Federal de Seguridad. Versión Pública de Felipe Mortera. Caja 305, f. 82. AGN, México.

${ }^{42}$ Una nota esclarecedora del primer asunto referido es: "Habla Gutiérrez Roldán del manejo de Petróleos", El Popular, 6 de diciembre de 1958, p. 1. Ahí señalaría: "Manejaré la industria de los hidrocarburos como una empresa privada, dedicada exclusivamente a mejorar la vida del pueblo mexicano". Por su parte Antonio J. Bermúdez (1988) señala: "se pretendió entregar la petroquímica básica a intereses privados inclusive extranjeros” (p. 60). 
El 2 de diciembre inició la nueva convención del sindicato donde Felipe Mortera leyó el informe final de su gestión bianual, siendo previsiblemente vitoreado por sus correligionarios. Señalaba Mortera que la revisión del contrato colectivo no se había realizado debido a las circunstancias especiales del país (refiriéndose a la situación económica), pero que se había obtenido un aumento salarial para trabajadores y jubilados. Desde luego no se refería a que este "logro" se había debido a la presión ejercida por el grupo opositor y aprovechó para descalificarlos por sus reacciones "poco cuerdas, casi turbulentas". ${ }^{43}$

De manera paralela, los independientes realizaron otra convención en las instalaciones de la sección 34 con asistencia de delegados de las secciones: $10,11,22,23,24,26,30,31,34$ y 35 . No obstante que la reunión no era reconocida por las Secretarías de Gobernación y del Trabajo, la idea de los organizadores era presionar para que se anulara la convención "oficial" y hacer visible la antidemocracia que se vivía en el sindicato petrolero, por ello se envió un comunicado al presidente de la república, a la Secretaría del Trabajo y al director de Pemex solicitando un recuento en las votaciones sindicales internas. ${ }^{44}$

Como era obvio esperar, las autoridades federales dieron el espaldarazo a la reunión oficial. El día 4 el ingeniero Gutiérrez hizo acto de presencia en la sede oficial del STPRM, en donde leyó un discurso llamando a la cooperación y al patriotismo: "en Pemex seremos libres y ordenados", sentenció de manera determinante. Enseguida fueron ratificados los representantes de todas las secciones, menos de la 35 disputada por los "chimales". ${ }^{45}$

Sin embargo, las presiones tuvieron efecto de nuevo y se determinó hacer nuevas elecciones en ambas secciones, aunque de manera paralela a la Asamblea Nacional, ello con la clara intención de que los opositores no participaran de la elección del nuevo secretario nacional del stPRM. ${ }^{46}$ Así las

43 "Fue aprobado el informe del diputado Mortera", El Nacional, 9 de diciembre de 1958, p. 1.

${ }^{44}$ Véanse "Dos convenciones del stPRM: la buena y la chica", El Universal, 3 de diciembre de 1958, p. 1, y “Los 'chimales' van de mal en peor al intentar un golpe”, El Nacional, 7 de diciembre de 1958, p. 1. De acuerdo con Reyna y Trejo (1981, pp. 139-140) la reunión de los independientes era encabezada por Enrique Castillo de Poza Rica, incluso señala que esta reunión habría sido interrumpida por agentes policiacos.

${ }^{45}$ Véanse "Exhortación del Director de Pemex a los trabajadores de la industria", El Nacional, 5 de diciembre de 1958, p. 1, y "Asistió el Ing. Gutiérrez Roldán a la X Convención del sindicato petrolero", El Universal, 5 de diciembre de 1958, p. 1.

${ }^{46}$ De hecho al iniciarse la asamblea con la presencia del ingeniero Pascual Gutiérrez, director general de Pemex, un grupo de inconformes, encabezados por Enrique Castillo de Poza 
cosas, el 12 de diciembre, poco antes de las once de la mañana, Felipe Mortera desconoció ante la Asamblea Nacional a la planilla de la sección 34 y convocó a nuevas elecciones que se realizarían de manera inmediata; se trataba de un albazo. Al mismo tiempo miembros del grupo Movimiento de Acción Sindical, afín a Mortera, se apoderaron del cine Clavería donde debía efectuarse la elección. Ello mientras continuaba la X Convención Nacional. ${ }^{47}$

En estas condiciones se efectuaron las elecciones. Por los independientes se postuló Alfredo Renstrom Nilson, y por el lado oficial, Ismael Cerecedo Barrera. La consulta se desarrolló plena de anomalías, en esta ocasión no hubo autoridades de la Secretaría del Trabajo ni de Gobernación que sancionaran el proceso, ni fuerza pública que resguardara el orden. Lo que sí hubo fue un grupo de choque que se apoderó del edificio sindical, impidiendo el acceso a los seguidores de los "Chimales", por lo cual la elección terminó convertida en un zafarrancho violento. Hubo pedradas y balazos resultando siete heridos por arma de fuego, cuatro autos quemados, el cine Clavería destruido y detenidos Alfredo Renstrom Nilson y cuatro más de sus seguidores. ${ }^{48}$

En paralelo la Asamblea Nacional había electo como nuevo secretario general a Pedro Vivanco, de Poza Rica, al tiempo que se integraban representantes de casi todas las secciones al nuevo Comité Ejecutivo. ${ }^{49}$ Vivanco tenía

Rica y Miguel Hernández Alcalá, se acercaron con el fin de pedir que se invalidara la Asamblea Nacional debido a que muchos representantes seccionales eran espurios. Asimismo solicitaban que se suspendieran las nuevas elecciones de las secciones 34 y 35 . Al respecto véase la nota: "Propósitos de mutuo entendimiento de los petroleros y el director de Pemex", El Popular, 5 de diciembre de 1958, p. 1.

${ }^{47}$ Véanse las notas: "Suspensión de los directivos de la sección 14 de petroleros", El Nacional, 13 de diciembre de 1958, p. 1; "Ayer se registró un violento zafarrancho en la sección 35", El Popular, 14 de diciembre de 1958, y "Sangriento zafarrancho impidió la elección de los petroleros", El Universal, 14 de diciembre de 1958, p. 1. En cuanto a Roldán Vargas, señalado en esta nota como contratista, se sabe que hacia 1949 había sido impuesto por el gobierno federal encabezado por Miguel Alemán, como secretario general del STPRM, en lo que se conoció como el "charrazo". Moreno Andrade (2007) abunda: "[Gustavo Roldán Vargas] quien traía acusaciones en su contra de malversación de fondos y venta de plazas" (p. 96). Torre (1988) ha referido este pasaje en su cuento "La tarde de las pedradas".

${ }^{48}$ Hubo varias denuncias contra las actividades violentas realizadas por Gustavo Roldán Vargas y seguidores. Llegaron a la oficina de la presidencia, vía telegrama, varias protestas de grupos de petroleros y seguidores del movimiento depurador, denunciando las agresiones e incluso mencionaban el secuestro de Renstrom. Fondo Adolfo López Mateos. Legs. 1 y 6, exp. 433/5. AGN, México.

49 "Fue electo el Comité Nacional Petrolero", El Popular, 16 de diciembre de 1958, p. 1; "Vivanco nuevo líder en el STPRM”, Excélsior, 16 de diciembre de 1958, p. 1. 
un corte similar a Mortera; en Poza Rica había sido presidente municipal, se le señalaba por hacer negocios con el superintendente de la refinería del lugar, el ingeniero Jaime Merino, verdadero cacique local..$^{50}$ Más aún, ambos estaban acusados de la muerte de cinco personas en protestas sucedidas en octubre de ese año.

Así, los "Chimales" fueron despojados del control de la sección 34 y sólo pudieron retener la 35. De inmediato se hizo una nueva estrategia con dos objetivos centrales: el primero era rescatar a los líderes presos, lo cual se logró eventualmente, ${ }^{51}$ y el segundo fue expandir el movimiento depurador por todo el país. Ello implicaba otro tipo de movilización y un planteamiento ideológico más elaborado. En función de ello, Enrique Castillo, los "Chimales", y otros más, viajaron a Tampico para hacer campaña en contra de Vivanco iniciando una "cruzada" por democratizar el sindicato sobre tres líneas centrales: 1) defender el carácter nacional de la empresa; 2) garantizar las revisiones del contrato colectivo, y 3) reformar los estatutos para propiciar una representación democrática. ${ }^{52}$ En Poza Rica el movimiento cobró importancia con Castillo y Gabriel César Trejo, al igual que en Salamanca con Nicolás Rodríguez, ${ }^{53}$ mientras que en Minatitlán estaba Maximino López Guillén en representación de los depuradores. ${ }^{54}$

Paralelamente el movimiento buscó un canal de entendimiento con el nuevo presidente de la república, aunque eran señalados sus diferendos con el secretario de Trabajo. Tal vez una prueba de este intento de acercamiento es una interesante carta dirigida a López Mateos por la dirigencia del "Movimiento Depurador Nacional del STPRM”, entre cuyos firmantes aparecen: Carlos Castillo, Libio Sosa, Jesús Ibarra Olivares, y otros. Ahí se comentaba: "Los trabajadores petroleros, conscientes del elevado significado nacional de la industria petrolera, generalmente no hemos prestado atención a las prácticas extrañas que nos incitan a la protesta violenta y tumultuaria" (las cursivas son

50 En relación con el caso de Merino, véase Palacio Langer (2016).

51 Al respecto se dio una movilización ante Fernando Román Lugo, procurador del Distrito Federal. Algunas notas esclarecedoras: "Terminó la reunión de los petroleros. Con la suspensión de los chimales volvió la calma al gremio”, El Universal, 17 de diciembre de 1958, p. 1, y "Consignación de los petroleros escandalosos", El Universal, 18 de diciembre de 1958, p. 21.

52 "Campaña depuradora en el sindicato de Pemex", El Popular, 20 de enero de 1959, p. 1.

53 Fondo Adolfo López Mateos. Exps. 437.3/6 y 703.4/379. AGN, México.

54 Fondo Adolfo López Mateos. Exp. 542.1/436. AgN, México. Reyna y Trejo (1981, p. 140) señalan que hubo eco en las secciones $1,3,10,11,22,23,24,26,30,31,35$ y 38, lo cual presenta un escenario mayor. 
mías). Como se ve adoptaban, prácticamente, el lenguaje de sus detractores. Es probable que con este cambio de estrategia se pretendiera inhibir nuevos intentos de represión. Sin embargo, el grupo se mantuvo en pie por la democratización del sindicato y porque se reconociera su movimiento: "A los trabajadores petroleros se nos han arrebatado nuestros derechos sindicales esenciales, especialmente el de elegir a nuestros representantes; en tal forma carecemos de la posibilidad de colaborar mejor en la defensa, consolidación y progreso de la industria petrolera nacionalizada. ${ }^{55}$

\section{LAS TÁCTICAS DEL GOBIERNO ANTE LA PROTESTA PETROLERA}

Sin embargo, estos eventos sugerían otra lectura además de la subordinación del sindicato. Se observaba también la incapacidad de la dirigencia del STPRM para controlar la inconformidad interna. Fue así que los líderes independientes lograron sobrevivir manteniendo su activismo a lo largo del sexenio de Adolfo López Mateos. Así, llevaron a cabo movilizaciones en 1959 en Tampico y en Poza Rica. Para 1960, en las secciones de la ciudad de México, se realizó un planteamiento más elaborado cuyos puntos centrales eran: 1) Defensa de la industria nacionalizada (ante la manifiesta política del director de PEMEX, de propiciar inversiones extranjeras para desarrollar la petroquímica); 2) Revisión "decorosa" del contrato colectivo de trabajo, y 3) Reformar los estatutos para propiciar un sistema de auténtica democracia sindical. ${ }^{56}$

La movilización pareció rendir frutos, pues desde junio de 1959 Salvador Hernández e Ismael Cerecedo eran secretarios de las secciones 34 y 35 , respectivamente, y hacia el mes de octubre, cuando se efectuaron nuevas elecciones, el "Movimiento Depurador 27 de Agosto" postuló de nuevo a Carlos Castillo Delgado para la secretaría general de la sección 34; en la planilla también aparecía Nicéforo Pérez Cárdenas. En los pasquines propagandísticos se notaba un discurso moderado: "Vivimos una época extraordinaria, las prácticas viciadas y corrompidas para elegir funcionarios sindicales, no caben ya en

${ }^{55}$ Carta dirigida al licenciado Adolfo López Mateos por el Movimiento Depurador del Stprm. 10 de marzo de 1959. Fondo Adolfo López Mateos. Leg. 2, exp. 432/5. AgN, México.

${ }^{56}$ Véase "Campaña depuradora en el Sindicato de Pemex", El Popular, 20 de enero de 1959 , p. 1. 
nuestra Organización. Los métodos antidemocráticos han sido abolidos para siempre en la Sección 34". ${ }^{57}$ Castillo se impuso ampliamente reafirmando el control seccional para los otrora inconformes. Más aún, un reporte oficial señalaba que los "opositores" se mantenían disciplinados al CEN. ${ }^{58}$

El caso es que, para esos años, el "Movimiento Depurador 27 de Agosto" representaba un poder dentro de las secciones asentadas en la ciudad de México, que permanentemente conservaba comunicación con las autoridades federales. De hecho enviaban periódicamente información y documentos a la presidencia de la república, con dos intenciones: mostrar su control en la sección 34, y mantener un nexo con la autoridad para obtener su aval y evitar un nuevo ambiente de represión de la dirigencia del STPRM. ${ }^{59}$ A partir de entonces pareció darse una moderación en las acciones y demandas de los petroleros "independientes", desapareció la estridencia de su discurso y la fuerza de sus acciones.

Incluso, los líderes otrora opositores lograron insertarse en el Comité Ejecutivo Nacional, en donde Ismael Hernández fungió en 1962, como secretario de Organización y Estadística, justo cuando había asumido la secretaría general Joaquín Hernández Galicia "la Quina”. ${ }^{60}$

Tan hegemónicos se habían vuelto que cuando se dieron divisiones dentro del grupo, hacia 1961, los hermanos Hernández Alcalá descalificaron a su antiguo correligionario y asesor, el licenciado Juan Ortega Arenas, como trotskista "al servicio de intereses extraños", sin duda una argumentación muy cercana a la que se les había imputado antes por parte de las autoridades federales y el sindicalismo oficial. ${ }^{61}$

${ }^{57}$ Véase el impreso: A todos los trabajadores miembros y simpatizantes del Movimiento Depurador 27 de Agosto-Sector Oficinas. Fondo Adolfo López Mateos. Leg. 5, exp. 433/5. AGN, México. De hecho, este expediente contiene varios documentos que fueron enviados al presidente López Mateos por la propia dirigencia del "Movimiento Depurador 27 de Agosto".

${ }^{58}$ Según reportes: Dirección Federal de Seguridad. Versión Pública de Felipe Mortera. Caja 305, fs. 95-98. AGN, México.

${ }^{59}$ Fondo Adolfo López Mateos. Leg. 5, exp. 433/5. AgN, México.

${ }^{60}$ Dirección Federal de Seguridad. Versión Pública de Ismael Hernández Alcalá. Fs. 76-77. AGN, México.

${ }^{61}$ Tal declaración en Dirección Federal de Seguridad. Versión pública de Joaquín Hernández Galicia. 28 de julio de 1961. Leg. 2/6. AGN, México. Asimismo: "Juan Ortega Arenas, ex asesor del stPRm acusa a la cláusula 36", Proceso, 2152, 5 de noviembre de 1983. Otro evento que podría probar la cercanía al gobierno, se daría en 1968 cuando, durante el movimiento estudiantil, hubo brigadas de apoyo del sindicato a los estudiantes, sin embargo "los Chimales" no participaban de ello. Un comentario del director de Pemex en ese momento, Jesús Reyes Hero- 
Por otra parte, pareciera que la táctica del gobierno se inclinó más por la mediación, las dádivas políticas y económicas. Que se permitiera a "los Chimales" controlar las secciones 34 y 35, así como colaborar en el CEN del sindicato, resultaron acciones que les hicieron perder beligerancia. Todo indica que las autoridades del área laboral adoptaron una estrategia de hacer concesiones para, así, evitar la disputa por el control político de los trabajadores.

En cuanto a la dirigencia nacional, se dio una mayor colaboración; prueba de ello fueron las revisiones del contrato colectivo en 1961 y en 1963, que se habrían dado de manera extremadamente fluida. ${ }^{62}$ Así, el 23 de julio de ese año se publicó un desplegado firmado por la plana mayor del STPRM, dirigido al presidente, al secretario del Trabajo y al director de PEMEX. Al borde de la lambisconería, señalaban su agradecimiento al presidente "por la forma tan digna en que supo aquilatar y valorar las aspiraciones del sector petrolero, brindándonos su apoyo y depositando en nosotros su confianza, la cual no ha sido ni será nunca defraudada" ${ }^{63}$ Con ello parecía quedar sellado el tiempo de los exabruptos y de las confrontaciones sindicato-empresa. El sistema había encontrado a su hombre fuerte para el sector petrolero, ese era y lo sería, por los siguientes 25 años: "la Quina".

\section{CONSIDERACIONES FINALES}

La movilización de los petroleros afiliados a las secciones 34 y 35 de la ciudad de México, al igual que otros movimientos de finales de la década de los cincuenta, tuvo su motivación en el agravamiento de la situación económica, pérdida del poder adquisitivo del salario y falta de la revisión del contrato colectivo de trabajo. Aunque algunas de estas demandas fueron solventadas, muy pronto la movilización tomó el camino de la protesta política, que se manifestó en contra de las representaciones espurias del STPRM. Las inconformidades

les, señalaba al respecto: "Director de Pemex habla a secretario de Gobernación pidiéndole no vaya a detener a los Chimales, quienes, a pesar de tener pariente herido [el 2 de octubre] están colaborando" (Reyes, 2015, p. 104).

${ }^{62}$ Véanse "Se firmó esta madrugada el nuevo contrato colectivo de PEMEx con sus obreros”, El Día, 19 de julio de 1963, p. 1, y “Quedó firmado el contrato de Pemex”, El Universal, 19 de julio de 1963, p. 1.

${ }_{63}$ "Este desplegado se publicó en toda la prensa nacional. Sindicato de Trabajadores Petroleros de la República Mexicana”, Excélsior, 24 de julio de 1963, p. 15. 
con los líderes y con las posiciones oficialistas del sindicato y de las centrales obreras se convirtieron, en el fondo, en un cuestionamiento al sistema. ${ }^{64}$

La protesta de los petroleros demostró que la estrategia de integración política ejercida larga e intensamente por el Estado mexicano, tenía sus límites. De tal forma que la aparente coincidencia o alianza entre movimiento obrero y gobierno estaba sujeto a escrutinio constante. El ambiente de protesta de 1958 mostró que el pacto entre sindicatos y gobierno debía revisarse.

Por su parte, la estrategia de los petroleros disidentes incluyó el asambleísmo, una potente movilización, el paro, la huelga, y la alianza con otros sectores sociales también en pugna con el Estado. Sin embargo, el movimiento renovador que encabezó la protesta no fue exitoso en su intención por expandir su propuesta depuradora, por el contrario, pareció encapsularse en las secciones de la ciudad de México o bien entre algunos sectores vinculados a la izquierda política del país.

Paradójicamente, para los años sesenta ya era un hecho que este grupo -otrora de protesta- había claudicado. Ya entonces estaba penetrado y absorbido por la nueva dirección nacional del STPRM; fue en este momento que el grupo perdió su carácter contestatario, pues se había convertido en el eje hegemónico de las secciones 34 y $35 .^{65}$

Es notorio que las movilizaciones más importantes de este periodo se dieran precisamente entre agrupaciones que tenían una amplia práctica política y cuyo patrón era el Estado mismo. Sin embargo, en el caso de los petroleros hubo algunas particularidades. A diferencia de los maestros y ferrocarrileros, en donde la estrategia de control gubernamental incluyó claramente el descabezamiento de la dirigencia, con los petroleros se intentó una variante ante el "fracaso" de la solución de fuerza. De tal suerte se toleró que los insumisos y opositores a la dirigencia nacional del sindicato tomaran control de las secciones 34 y 35 asentadas en la ciudad de México.

Entonces, cabe preguntarse por qué el gobierno mexicano, que ya ensayaba "exitosamente" las medidas represivas como forma de control, decidió

${ }^{64}$ Para Loyo (1975): "No obstante no fueron las demandas económicas, sino sus derivaciones políticas, las que dieron a la crisis de 1959, su carácter francamente impugnador del sistema" (p. 358).

${ }^{65}$ Pérez Linares (1982). Esta visión contrasta con lo señalado por José Rivera Castro (1986): "Luego, bajo el gobierno de Adolfo López Mateos el ejército toma las instalaciones petroleras, encarcelando a los principales dirigentes, golpeando con ello a la insurgencia petrolera y abriendo una nueva etapa de control más férreo sobre los trabajadores" (p. 33). 
hacer una excepción en el caso de los petroleros. Me parece que imperaron varias cuestiones. Por una parte, el movimiento petrolero estaba razonablemente focalizado en la ciudad de México y no significaba un riesgo real de extenderse por todo el país.

Asimismo, debe considerarse que el gobierno, aunque rechazaba la protesta, fue más tolerante hasta en tanto no se efectuara el proceso electoral y el relevo en la presidencia de la república. Claramente a partir del cambio de administración se mostró más restrictivo. La estrategia de las autoridades federales pareció inclinarse por el fortalecimiento de una dirigencia nacional que en lo sucesivo controlara las constantes fracturas y disputas internas del STPRM, y que hasta los finales de la década de los cincuenta había sido ineficaz en ese sentido. Los métodos de control serían diversos e irían desde la corrupción de líderes, el chantaje, la amenaza, la infiltración de grupos "disidentes", el porrismo o la cooptación mediante el otorgamiento de puestos de control sindical. La ejecución de estas tareas estuvo a cargo de Joaquín Hernández Galicia, secretario nacional del STPRM; a partir de entonces empezó a fincar un poder omnímodo e indiscutido.

Otro ámbito de estrategias residió en las medidas de fuerza, en el descabezamiento de los movimientos de ferrocarrileros y maestros, cuyos líderes fueron recluidos en la cárcel acusados de disolución social. También funcionaron la amenaza de requisa a empresas estatales (como sucedió con los telefonistas), mientras que la declaratoria de ilegalidad de las huelgas hicieron otro tanto. La descalificación ideológica hizo también una parte; las acusaciones -en ocasiones falsas- de afiliación al comunismo fueron un argumento eficaz ante la sociedad para descalificar movilizaciones cuyos reclamos se inscribían en los postulados de la Constitución. Sin embargo, el Estado también aplicó el otorgamiento de concesiones materiales y políticas que ayudaron a cooptar líderes y bases. Así, en 1959 se creó el ISSSTE y en 1962 se reglamentó el apartado "A" del artículo 123 relativo a los salarios mínimos, reparto de utilidades y otros asuntos. Reyna y Trejo (1981) señalan al respecto:

La lección que dejan los sucesos de 1958-1959 fue, en apariencia, más positiva para el Estado que para el movimiento obrero organizado. Los mecanismos de control político se afinaron: la demostración de esto yace en el hecho de que no se volvería a dar una protesta obrera de la magnitud y de la intensidad como la ocurrida en esos años. La solución de la crisis robusteció las instituciones 
políticas y el control que de estas emana. El conflicto sirvió para que el Estado orientara más hacia la prevención de los conflictos (p. 85).

Asimismo, en los arreglos logrados entre sindicato, empresa y gobierno no es desdeñable cierta intención negociadora de los líderes de las secciones de la ciudad de México, quienes también ensayaron un esquema de acercamiento a las autoridades, lo cual probablemente constituya un contraste con los ferrocarrileros y maestros que se habrían mostrado más intransigentes. Por todo lo señalado, el movimiento de los petroleros configuró un caso especial en las formas de control ejercidas por el Estado mexicano.

\section{LISTA DE REFERENCIAS}

Aguilar, J. (coord.) (1986). Los sindicatos nacionales. Petroleros. México: CV Editores.

Alzaga, O. (2007). Semblanza de Mario Pavón Flores, testigo y protagonista del movimiento obrero. Alegatos, 21(67), 399-430. Recuperado de http://alegatos.azc.uam. $\mathrm{mx} /$ index.php/ra/article/view/458

Barbosa Cano, F. E. (1979). PEMEX: problemas laborales en el periodo de la reorientación de la industria al mercado interno (Tesis inédita de licenciatura). Universidad Nacional Autónoma de México, México.

Basurto, J. (1984). La clase obrera en la historia de México, del ávilacamachismo al alemanismo (1940-1952) (vol. 11). México: Editorial Siglo XXI/Instituto de Investigaciones Sociales-UnAm.

Bermúdez, A. J. (1988). La política petrolera mexicana. México: Petróleos Mexicanos.

Bravo Flores, Á., Rendón Corona, A. y González Rodarte, J. (1997). Los conflictos laborales en la industria petrolera y la expropiación 1933-1938. México: UAM-Iztapalapa.

Brown, J. C. (2000). Workers' control in Latin America, 1930-1979. Carolina del Norte: The University of North Carolina Press.

Canales Ucha, C. (1979). Sin salida. El caso de los trabajadores petroleros transitorios de Pemex (Tesis inédita de licenciatura). Universidad Nacional Autónoma de México, México.

Caulfield, N. (1998). Mexican workers and the State. From porfiriato to NAFTA. Texas: Christian University Press.

Chávez Padrón, M. (1988). Testimonio de una familia petrolera. México: Petróleos Mexicanos.

Corro, S. (1989). La Quina, el lado oscuro del poder. México: Grupo Editorial Planeta. 
Hernández Ayala, S. (1991). El sindicato, su autonomía y desviaciones: el caso del sindicato petrolero (Tesis inédita de licenciatura). Universidad Nacional Autónoma de México, México.

Herrera Montelongo, J. (1998). Colaboración y conflicto. El sindicato petrolero y el cardenismo. México: UAM-Azcapotzalco.

Leal, J. F. (1976). México: Estado, burocracia y sindicatos. México: Ediciones El Caballito/ Centro de Estudios Latinoamericanos, Facultad de Ciencias Políticas-unam.

Loyo, A. (1975). El marco socioeconómico de la crisis política de 1958-1959 en México. Revista Mexicana de Sociología, 37(2), 349-362. DoI: 10.2307/3539387

Medina, L. (1982). Historia de la revolución mexicana 1940-1952. Civilismo y modernización del autoritarismo (vol. 20). México: El Colegio de México.

Meyer, L. y Morales, I. (1990). Petróleo y nación (1900-1987). La política petrolera en México. México: fCe/Pemex/semip/Colmex.

Moreno Andrade, S. H. (2007). Dilemas petroleros. Cultura, poder y trabajo en el Golfo de México. México: ciesas.

Ortiz Mena, A. (1998). El desarrollo estabilizador, reflexiones sobre una época. México: El Colegio de México/Fondo de Cultura Económica.

Palacio Langer, J. del (2016). Jaime Merino. The oil cacique of Poza Rica, Veracruz, 1941-1959. The Extractive Industries and Society, 3(2), 426-434. DoI: 10.1016/j. exis.2016.01.009

Pellicer de Brody, O. y Reyna, J. L. (1981). Historia de la revolución mexicana 1952-1960. El afianzamiento de la estabilidad política. México: El Colegio de México.

Pérez Linares, R. (1982). Charrismo y burocracia sindical en la década de los setenta. El sindicato petrolero (Tesis inédita de licenciatura). Universidad Nacional Autónoma de México, México.

Pozas Horcasitas, R. (2015). El desarrollo de la seguridad social en el gobierno de Adolfo López Mateos. En R. Hernández Rodríguez (coord.), Adolfo López Mateos. Una vida dedicada a la política. México: El Colegio de México.

Reyes Heroles, F. (2015). Orfandad: el padre y el político. México: Alfaguara.

Reyna, J. L. y Trejo Delarbre, R. (1981). La clase obrera en la historia de México. De Adolfo Ruiz Cortines a Adolfo López Mateos (1952-1964). México: Instituto de Investigaciones Sociales-UNAM.

Rivera Castro, J. (1986). Periodización del sindicalismo petrolero. En J. Aguilar, Los sindicatos nacionales. Petroleros. México: CV Editores.

Samgrae Lim, Y. (1994). Los trabajadores y el Estado (los petroleros mexicanos) (Tesis inédita de licenciatura). Universidad Nacional Autónoma de México, México. 
Tello, C. (2007). Estado y desarrollo económico: México 1920-2006. México: Facultad de Economía-UNAM.

Torre, G. de la (1988). Relatos de la vida obrera. México: Secretaría del Trabajo y Previsión Social.

Valdivieso, C. (1963). Historia del movimiento sindical petrolero en Minatitlán. Veracruz: Talleres de la Imprenta Mexicana.

Womack jr., J. (2007). Posición estratégica y fuerza obrera. Hacia una nueva historia de los movimientos obreros. México: Fondo de Cultura Económica.

Zapata, F. (1993). Autonomía y subordinación en el sindicalismo latinoamericano. México: El Colegio de México/Fondo de Cultura Económica.

\section{OTRAS FUENTES}

Archivos

AGN Archivo General de la Nación, México.

CEmos Centro de Estudios del Movimiento Obrero y Socialista, México.

\section{Hemerografía}

El Nacional.

El Popular.

El Universal.

Excélsior.

Novedades.

Proceso.

\section{Bibliografía}

López Villegas, V. (1990). El periodo de la unidad nacional y de la segunda guerra mundial. 1940-1946. En J. Aguilar (coord.), Historia de la CTM, 1936-1990 (t. I). México: IIS-UNAM.

Novelo, V. (1991). La difícil democracia de los petroleros: historia de un proyecto sindical. México: cIesAs/Editorial El Caballito. 